\title{
Research on Smart Education of Accounting Major in Colleges and Universities from the Perspective of Integration of Production and Education*
}

\author{
Liping $\mathrm{Hu}$ \\ Hubei Business College \\ Wuhan, China
}

\begin{abstract}
The integration of production and education is an inevitable requirement for university education in order to realize economic transformation and development and adjust regional industrial structure, and is also the key path for deepening the connotative construction of higher education. Through smart education of accounting major in colleges and universities, it can not only realize resource sharing and utility maximization but also is the key to improve school's core competitiveness. Colleges and universities should carry out the construction of smart education for accounting major based on the mode of "integration of production and education". Moreover, it is also necessary to focus on the professional positions, make scientific arrangement on a group of specialties, create new talent cultivation mode, realize a school-enterprise integrated education mode, construct a scientific and rational curriculum system for a group of specialties, and develop a shared, open and interactive digital resource library; in addition, school and enterprise should jointly build up diversified teaching teams and shared training bases to promote the cultivation of high-quality, skilled and compound innovative talents.
\end{abstract}

Keywords-integration of production and education; accounting major in colleges and universities; smart education

\section{INTRODUCTION}

Accounting education in colleges and universities should focus on cultivating students' "professional skills" and improving their abilities to apply technologies. Therefore, the combination of theory and practice is the training work that must be implemented in university accounting education. However, in the work of university accounting education, there is a common phenomenon that theoretical teaching is paid more attention to than practical training on post; although some colleges and universities have attempted at the integration of production and education, most of them do not go further or deeper into the mode so that practical training is often conducted superficially and doesn't reach the expected cultivation effect. With the development of information technology, it has already been imperative to explore the smart education based on the cultivation mode

*Fund: School-level teaching and research project of Hubei Business College "Research on Smart Education of Accounting Major in Colleges and Universities from the Perspective of Integration of Production and Education" (project No. JY201810). "integration of production and education" in order to improve the level of accounting education in colleges and universities, and promote the growth and development of students in future work.

\section{OVERVIEW OF THE INTEGRATION OF PRODUCTION AND EDUCATION}

\section{A. Connotation}

The mode of "integration of production and education" (hereinafter referred to as the "Integrated Mode") is a kind of teaching mode emerged in recent years. It refers to the combination of teaching in classroom and training in business entity in the process of talent cultivation to achieve a win-win situation between school and enterprise. Due to the ever-changing nature of the society in development, the requirements for talents in the industry cannot be fixed. Students' professional ability and quality will be difficult to cope with corresponding job positions if they are merely taught on the basis of the teaching syllabus. The Integrated Mode is to let employers participate in professional education and provide students with learning resources by means of practical training. In this process, higher vocational colleges and employers can be supported and promoted mutually, and constantly create new teaching methods and means to promote the development of higher vocational education. At the same time, in the Integrated Mode, it is also needed to pay attention to five dockings including the docking between profession and the industry, between teaching and production, between curriculum and vocation, between education background and vocational ability, and between higher education and lifelong learning. In this teaching mode, the employer provides the bases and posts for practical training, which greatly enriches the teaching resources of colleges and universities. At the same time, good cooperation between the two sides is also of great significance to improve the employment rate of students. For employers, a large number of talents can be attracted in the process of the integration and colleges have also gradually become their assistant force for making scientific research so that the development of the enterprises can also be positively promoted. 


\section{B. Importance}

In fact, the Integrated Mode had early been required by the Ministry of Education in the end of the last century, and further emphasized by President Xi Jinping in the report of the 19th National Congress; the Integrated Mode has been widely recognized as a concept and policy for running a school. First of all, the implementation of the Integrated Mode can improve the professionalism of vocational students. Since the beginning of the 21 st century, China has carried out many enrollment expansions in order to realize the popularization of higher education. Although this practice is conducive to realizing the fairness of education, the professional qualities of students naturally appear differently, compared with elite higher education. However, the Integrated Mode can help getting this situation effectively improved by cultivating students' ability to apply technologies. Secondly, the Integrated Mode is also conducive to the transformation and upgrading of enterprises. After decades of rapid development, China has become an economy just next to the United States. However, from the perspective of industrial structure, most enterprises in China engage in labor-intensive industries, and have relatively weak added value and competitiveness in terms of products. The Integrated Mode can dock vocational education with production, to effectively improve the innovation ability and application ability of talents and achieve the goal of enterprise for development and transformation. Finally, implementing the Integrated Mode in professional teaching is also crucial for promoting the development of China's vocational education and boosting the strategy for macro development of China. In recent years, "market orientation" has always been a hot topic of research. The combination of production and education makes higher vocational students more in line with the needs of the talent market. Meanwhile, the Integrated Mode is also related to the optimization of China's development direction and industrial structure from macro aspect and helps to lay a solid foundation for future economic development of China.

\section{OVERVIEW OF SMART EDUCATION}

\section{A. Generation}

Smart education is generated with the demand for information-based development of education. Nowadays, as smart cities begin to emerge, smart education has also gradually come into being. Smart education is an interconnected, intelligent, perceptive and generalized educational information system created on the basis of a new generation of information technologies such as Internet of Things, cloud computing and wireless communication. It is a new realm of the information-based development of contemporary education, and the important goal pursued by modernization of education. The talent quality, technological development level and application and innovation abilities of colleges and universities provide the foundation and guarantee for the development of smart education, making colleges and universities become the foregoers, pioneers, demonstrators and leaders of smart education. To promote smart education, it is necessary to realize a deep integration of information technology and education business in the core elements such as smart environment, smart teaching, smart learning, smart management, smart evaluation, and smart service, and further improve the satisfaction of education stakeholders such as students, teachers, parents, managers, and the public. Smart education and accounting have the common technical foundation (such as cloud computing) and the same goals (namely, improving the effectiveness of teaching and the utilization efficiency of educational resources).

\section{B. Connotation}

IBM firstly put forward the concept of smart education and pointed out that the connotation of smart education: namely smart education is student-centered, provides diversified interactive experience, and can realize real-time statistics and analysis, make scientific allocation, centralized management and real-time monitoring on teaching and educational resources, support making statistical analysis from many points of view and levels such as the stakeholders, make integrated management, conduct integrated operation and processing of the teaching and management process, provide intelligent management on teaching equipment, make complete record and management on individual and group education information, share highly integrated resources and can also provide excellent resources accessible anywhere and at any time.

\section{WAYS TO IMPLEMENT THE CONSTRUCTION OF SMART EDUCATION ON ACCOUNTING MAJOR IN COLLEGES AND UNIVERSITIES FROM THE PERSPECTIVE OF THE INTEGRATION OF PRODUCTION AND EDUCATION}

\section{A. Focusing on the Professional Positions and} Scientifically Making Arrangement on a Group of "Onecore, Two-wing" Specialties

Accounting specialty of Hubei Business College has strong faculty and high employment rate. It is a key specialty of the school, plays a leading and core role in the group of specialties, focuses on "broad base and super-hard skills", and has extensive employment adaptability. Financial management specialty and auditing specialty are gradually developed on the basis of the excellent quality of teachers of accounting specialty. The former specialty focuses on the market demand for high-end financial talents and has the characteristics of high value and tight industrial demand, while latter specialty echoes to the current market's continuous rising demand for auditing talents and has broad employment prospects. The three specialties have formed a cross-integration and resource sharing mode in terms of curriculum setting, teacher staffing, training bases and school-enterprise cooperation. Therefore, getting the above three specialties integrated into the construction of the group of accounting specialties is conducive to forming professional cluster advantages as well as the uniform planning and coordinated development of professional construction, so as to meet the demands of vocational positions for professional talents. 
B. Following the Development Law of College Education and Creating a Talent Cultivation Mode That Pays Equal Attention to Morality, Ability and Quality, Realizes the Docking Between Post, Curriculum and Certificate, Combines Match and Teaching, Guidance and Teaching, and Integrates Practice with Learning

In this regard, the following aspects should be conducted: the first is to get students' professional ethics and integrity placed in the first place and enhance their professional ability training and comprehensive quality improvement; the second is to set up curriculum on the basis of specific working positions, get the content of vocational qualification test and vocational skill standards incorporated into the curriculum system, realize the combination of curriculum standards and vocational qualification standard, and lead the teaching reform and curriculum construction by means of "doublecertificate" system to practically dock post with curriculum and certificates; the third is to a new mode of education and teaching in the information-based environment, cultivate students' good habits of active participation, exploration and diligent hands-on ability through scenario creation, problem exploration, negotiated learning, meaning construction and other student-centered process design so as to let students master knowledge and skills through practice, play the organizing and leading role of teachers and realize a combination of guidance and teaching, and a unification between learning and practice and between knowledge and behavior. With the support of modern information technology, it is necessary to actively explore the application of informatization means such as WeChat, online MOOC, micro-course, Weibo, cloud-class classroom, hotline interview, etc. in classroom teaching, and carry out flipped classroom teaching reform to stimulate students' interest in learning and improve the teaching effect on classroom. Moreover, it is also feasible to institutionalize and normalize the skills competition on the basis of the "combining match and teaching to promote teaching and learning" concept, organize students participating in various skills, innovation and entrepreneurship competitions and form a benign interaction with daily teaching. With the reform and innovation in talent cultivation mode, students have been effectively improved in practical ability and innovative ability, and achieved outstanding results in various accounting skill competitions at all levels.

\section{Strengthening the In-depth Integration of Production and Education, and Creating a New Talent Cultivation Mechanism Under School-enterprise Integration}

In this aspect, the following points should be conducted: the first is to establish an in-depth school-enterprise integration mechanism and set up a "Steering Committee for Specialties of Accounting" to jointly conduct the construction of the group of specialties, as well as curriculum reform and teaching work; the second is to actively explore new mode and new path combining practice and learning and introduce it to school. At present, responsible person of accounting specialty of Hubei Business College is negotiating with a number of enterprises, and plans to establish a proxy bookkeeping studio, together with the enterprise under the school-enterprise cooperation, as the basis for implementing the modern apprenticeship system for accounting major, so that students can conduct a work-based learning under the joint guidance of dual tutors, realize seamless docking with the working post; this mode creates a new mode of talent cultivation through school-enterprise integration, and also provides a good platform for teachers to put knowledge into practice, practice themselves on post in an enterprise and conduct practical teaching, realizing a winwin-win situation between school, enterprise and students. The wide-ranging specialties based cultivation mechanism and the school and enterprise integrated talent cultivation mode make it available to improve students' adaptability on working post, so that students graduated from the financial and economic department can be favored by employers.

D. Taking the Gradual Progression in Ability as the Main Line and Constructing a Curriculum System of "Sharing at Basic Level, Separation at Middle Level and Mutual Selection at Senior Level" for a Group of Specialties

According to the specific "service orientation" of financial posts, this study makes an in-depth analysis on the commonality and difference of the core professional courses and related professional courses in the group of specialties, and introduces the industrial standard for working in enterprises and technical standard for accounting major; it is suggested to take the gradual progression in ability as the main line and construct a work process oriented curriculum system of "sharing at basic level, separation at middle level and mutual selection at senior level" for a group of specialties, with the purpose of getting typical work tasks in financial working post converted into the learning programme, so as to incorporate the content of accounting specialized skills test into the curriculum and realize the docking of curriculum with vocational certificate. Moreover, it is advised to formulate curriculum criterion emphasizing professional ability cultivation, as well as teaching evaluation and assessment criterion, together with enterprises in the industry, to practically dock the teaching content with corresponding working post and realize the integration of the curriculum criterion and vocational qualification standard.

\section{E. Developing a Hierarchical Digital Resource Library in \\ Stages in the Principle of Co-construction, Sharing, and Openness}

Taking the Steering Committee for Specialties of Accounting as the platform, school and enterprise can jointly establish a development team, create a shared and opened professional center, curriculum center and material center based three-level digital resource library and information platform, and form a management mode "under the charge of special person and participated by all staffs". Wherein, the professional center is constructed in a way focusing on professional standard library, professional information database and school-running basic library; the curriculum center focuses on four courses, such as vocational qualification test courses, general core courses, professional skills training courses, and professional expansion courses, develops all levels of exquisite courses, online courses, MOOCs and micro-courses, and constructs a digital curriculum resource library involving teaching design, 
teaching implementation and teaching evaluation; and the material center is a collection of basic material resources mainly in forms such as text, chart, animation, and video constructed on the basis of the resource elements of various courses, and also a collection of special material resources having social service function and provided as per different demands of students, teachers and industrial workers. The construction of the digital resource library is conducted in stages while putting it into use to realize co-construction and sharing. At present, responsible person of the accounting specialty is discussing with the cooperation unit about the construction affairs.

\section{F. School and Enterprise Should Jointly Establish a Diversified Teaching Team, Create a Team of Double- professional Teachers to Optimize the Teaching Team, Dilute Its "Specialty", and Establish a Diversified School-enterprise Cooperative Teaching Team According to the Different Needs for Construction of a Group of Specialties}

In this aspect, it is suggested to do the following points: the first is to set up a curriculum teacher team to jointly make curriculum development, design and implementation. The second is to set up a skill coaching team to jointly carry out skill competition training activities and skill teaching activities, and lead famous teachers to form a studio team of famous teachers (professors), focusing on teaching research and teacher training, and exerting the demonstration, radiation and leading role. The third is to carefully recruit and cultivate responsible person of the group of specialties, the responsible person of each specialty and that of each course. Wherein, the responsible person of the group of specialties is mainly responsible for the overall planning and construction of the group of specialties, coordinating the development among various specialties within the group, implementing the dual-specialty leader system, selecting industrial experts as the professional leaders of enterprises, and jointly responsible for grasping and arranging the implementation of the specialty orientation together with the responsible person of each specialty; while the responsible person of each course focuses on reform of the teaching content and teaching mode and specifically responsible for teaching implementation and textbook development of each course. The fourth is to create a team of teachers combining full-time teachers and part-time teachers and cultivate a batch of backbone teachers by taking measures such as investigation, advanced studies, training and take a job in enterprise to practice, as well as actively explore the "mutual employment and mutual part-time job" exchange mechanism between school and enterprise, expand multiple channels, hire professionals with certain reputation and rich practical experience from industrial enterprises to serve as part-time teachers and undertake practical teaching, special lecture and internship guidance and other works, and take effective measures to constantly improve part-time teachers' teaching design and curriculum development ability.

\section{G. Integrating Practical Teaching Resources and Building a Shared Training Base}

In this aspect, it is needed to integrate existing oncampus resources and construct and manage the on-campus training bases together with enterprise on the basis of training for general skills of the group of specialties and special skills for each specialty, as well as conduct overall construction in forms of accounting training zone, enterprise operation training zone and inter-disciplinary comprehensive training center. Each functional zone is built to support a number of specialized training rooms for cultivating core job skills; in addition, it is also needed to introduce advanced accounting simulation software, create a vocational atmosphere in the financial industry, restore the work scene of accounting positions, and formulate enterprise-based teaching management system on the basis of the management system in financial industry. Furthermore, building an a professional accounting culture in line with the needs of both school and enterprise can help students to recognize spiritual culture and material culture of the specialty and promote their development of professional culture in a subtle way. The teaching requirement for practice on post can be met by deepening the cooperation between school and enterprise, establishing a series of "perceptual, follow-up, and employment-oriented" offcampus training bases, and exploring a practice and training base construction mode of "school-based enterprise and enterprise-based school".

\section{CONCLUSION}

All in all, smart education of accounting major in colleges and universities is a systematic and complex project, and the smart education in colleges and universities conducted on the basis of the integration of production and education is facing more challenges and difficulties. In the future, colleges and universities still need to constantly make exploration and innovation on how to construct smart education for accounting major by in-depth integration of production and education.

\section{REFERENCES}

[1] The State Council. National Outline for Medium and Long-term Education Reform and Development (2010-2020) [Z]. 2010.7. (in Chinese)

[2] Yang Shanjiang. A New Probe into the Roles of Institution, Enterprise, and Government in the Mode of "Integration of Production and Education" — Based on the "Triple Helix" Theoretical Framework [J]. Higher Agricultural Education, 2014(12). (in Chinese)

[3] Su Hua, Fang Xiangyang. Discussion on the "Integration of Production and Education" in Vocational Education from the Perspective of "Three-Party Subject" [J]. Education and Vocation, 2015(8). (in Chinese)

[4] Chen Zhaofang. Exploration and Practice of Professional Group Construction Based on the Integration of Industry and Education Taking the Construction of Accounting Professional Group as an Example [J]. Communication of Vocational Education, 2017(27). (in Chinese)

[5] Yao Li. Reform and practice of the talent training mode of "in-depth integration of school and enterprise and combination of work and 
study" in accounting major [J]. Chinese Vocational and Technical Education, 2013(8): 78-81. (in Chinese)

[6] Guo Hongxia. Research Summary of Smart Education in China from 2005 to 2015 [J]. Digital Education. 2016, 1. (in Chinese) 